Alkohol, Äther, Chloroform auf die besondere Affinität dieser Stoffe zum Nervensystem und die dadurch bedingte Anhäufung im Nervengewebe zurück.

Damit sind wir bereits in die Nähe derjenigen Narkosetheorie gelangt, welche als Lipoidtheorie der Narkose von $\mathrm{H}$ a $\mathrm{s} \mathrm{H}$ ors t $\mathrm{M}$ e ye $\mathrm{r}^{37}$ in Wien (1899) und dem eine Zeit lang in Zürich wirkenden englischen Botaniker Ch arles Ernest $O$ verton (1901) für einige Jahrzehnte eine tragbare, wenn auch nicht unbestrittene Geltung besessen hat.

\title{
Anaesthetic and other therapeutic properties of chloroform ${ }^{1}$
}

\author{
By J. Y.S i m p s o n, M. D., F. R. S.E. \\ Professor of midwifery in the university of Edinburgh, and \\ Physician-accoucheur to her Majesty in Scotland, etc. \\ From the monthly Journal of Medical Science, December 1847
}

At the first winter meeting of the Edinburgh Medico-Chirurgical Society (10 $10^{\text {th }}$ November), I directed the attention of the members to a new respirable anaesthetic agent which I had discovered a short time previously, - viz., Chloroform, Chloroformyle, or Perchloride of Formyle. In this limited notice, I shall state briefly some of the principal facts pertaining to its history, composition, effects, \& c.

${ }^{37}$ H. H. Meyer, Zur Theorie der Alkoholnarkose. 1. Mitteilung. Welche Eigenschaft der Anaesthetica bedingt ihre narkotische Wirkung? Arch. exper. Path. Pharm. 42, 109 (1899).

${ }_{38}$ E. Overton, Studien über die Narkose, zugleich ein Beitrag zur allgemeinen Pharmakologie. Jena 1901.

1 Die Wiedergabe dieses Originalaufsatzes von Simpson über Chloroformnarkose, eines einzigartigen und sehr selten gewordenen Dokumentes, erfolgt nach einem im Besitz der Zürcher Zentralbibliothek befindlichen Abdruck.

In diesem Zusammenhang sei auch auf den Aufsatz William Oslers: «The first printed documents relating to modern surgical anesthesia», in: Proc. Roy. Soc. Med. London 11, 65 (1917), und auf John F. Fultons: «The Morton and Warren Tracts on Ether (Letheon)», published as an appendix to: Thomas E. Keys, The history of surgical anesthesia, New York 1945, hingewiesen.

Mortons Memorandum an die Pariser Akademie vom 31. Juli 1847 wurde kürzlich durch J. F. Fulton in einem Neudruck herausgegeben: «A memoir to the academy of sciences at Paris on a new use of Sulphuric Ether by W.T.G. Morton of Boston in the USA Presented by M. Arrago in the autumn 1847. Henry Schuman, New York 1946.» (H. Fischer.) 
Chemical history and composition. - Chloroform was discovered at nearly the same time by Soubeiran (1831), and Liebig (1832). Its chemical composition was first ascertained by Dumas and Peligot (1835). It consists of 2 atoms of carbon, 1 of hydrogen, an 3 of chlorine; or, to express it otherwise, of 1 atom of formyle and 3 of chlorine. Hence its chemical formula is $\mathrm{C}_{2} \mathrm{H} \mathrm{Cl}_{3}$; or $\mathrm{Fo}_{3}$.

Modes of p repar a tion. - It may be obtained by various processes. 1. By the distillation of a mixture of diluted spirit, pyroxylic or wood spirit, or acetone, and chloride of lime (bleaching powder); or; 2 . By making milk of lime, or an aquous solution of caustic alkali, act upon chloral; 3 . By leading a stream of chlorine gas into a solution of caustic potass in spirit of wine, \& $\mathrm{c}$.

Phy sical and chemical propertit s. - It is a clear, limpid liquid, as heavy as 1,480 : not inflammable; very volatile; and boils at $141^{\circ}$. It has a fragrant fruitlike odour; and a sweet saccharine taste.

Th e ra p e u t i c h i s t o r y. - It has been used internally. Guillot employed it in asthma, diluted with water one hundred times (1844). My friend, Dr. Formby of Liverpool, told me, about two years ago, that he used it often in a diluted form as a diffusible stimulant; and I have, since that period, frequently prescribed it instead of valerian, camphor, \& c. ${ }^{2}$ But $I$ am not aware that any person has used chloroform by inhalation, or discovered its remarkable anaesthetic properties till the date of my own experiments.

A d vantages a s a a a e sthe tic a gent. - In producing insensibility to pain in surgical and obstetric practice, chloroform possesses various important advantages over sulphuric ether. 1. A greatly less quantity of chloroform is required; 2 . Its action is much more rapid, more perfect, and generally more persistent; 3 . Its exciting or exhilirating stage is far shorter, insensibility commonly supervening in a minute or two, or less; hence, 4 . The time of the surgeon is saved; 5 . The inhalation and influence of it are more agreeable and pleasant; 6. Its odour is evanescent; 7 . No special instrument is required for its employment.

Dose and mode of exhibition.-A fluid drachm or two of the liquid, diffused upon the interior of a pocket-handkerchief, arranged in a concave or cup-like form in the hand of the exhibitor, and applied over the nose and mouth of the patient, generally suffices to produce rapid and complete anaesthesia. A few patients may require more, others less. The edges of the cup or cone are not to be wetted, or the patients face will be irritated. To keep up its action, when that is necessary, the handkerchief must be again besprinkled with the fluid when the first quantity is evaporated. The moistened handkerchief should be at first held at the distance of about half an inch from the face, and gradually approached nearer. The patient should, if possible, be

${ }^{2}$ Since first publishing on the subject of chloroform, Dr. Glover of Newcastle has pointed out to me, that, in an essay on Bromine in the $152 \mathrm{~d}$ number of the Edinburgh Medical and Surgical Journal, he mentions having poinsoned several animals with chloroform, by injecting it into their bloodvessels, stomach, and the cavity of the peritoneum, and has investigated its physiological mode of action. 
placed easily and upon his back, and advised previously to take full inspirations. All noise and excitement around the patient should be strictly and peromptory forbidden. ${ }^{3}$

$P h y s i o l o g i c a l$ e f f e cts. After the first two or three full inspirations, a feeling of warmth and excitation, radiating from the chest to the extremities; followed by whirring noises in the ears; a sensation of vibratory thrilling and benumbing throughout the body; with, betimes, rapid loss of sensation and of motion, and at least of consciousness. Often before total unconsciousness supervenes, the patient, guided by instinct rather than by volition and reason, makes an effort to get rid of the inhaling vapour and handkerchief, as if it interfered with free respiration. This temporary effort must be resisted by the exhibitor. During the full anaesthetic sleep produced by chloroform, sometimes no mental action goes on, or at leat is remembered; in many others, the mind is active as in dreams. The respiration is usually at first soporose; the pupil is sometimes natural, in others slightly contracted, in others dilated; the pulse is usually quickened ten or twenty beats at first, but afterwards falls to its normal rate, and, if the vapour is exhibited very long in very powerful doses, it comes down more and more below the natural standard; muscles of voluntary motion in general relaxed; more rarely cataleptic; still more rarely clonically contracted, as happens also occasionally with ether.

In small doses, given slowly, its effects are exhilarating; and exactly like those generally following the inhalation of nitrous oxide gas. Of course, when exhibited in this way, the patient is in a state of excitement quite unfit for a surgical operation. When given for surgical operations, it should be exhibited rapidly in large doses, and the patient sent over into a deep soporose or sterterous sleep b e f o $\mathrm{r}$ e the incisions are begun. ${ }^{4}$

Us e s in s u r g e ry. - 1 . To relax the muscles in reducing dislocations \& e.; 2. To avert the sufferings attendant on deep probing, and ohter painful but necessary modes of diagnostic examination and dressing; and $3^{\mathrm{d}}$, and principally, to annul the pain of operations by the caustic, ligature or knife.

E $x$ a m p le s. - I. A child of ten weeks old had a very large naevus behind the ear. Dr. Duncan destroyed its internal organization by passing red-hot needles in different directions through it. While the tumour was hissing and decomposing under their action, the infant lay quietly and placidly asleep on my knee, under the influence of chloroform. This is the youngest subject to whom I have given it. - II. A boy, of four or five, had a necrosed radius cut down upon, and removed by Mr. Miller. He slept soundly during the

3 Nothing can be more absurd than the way in which some dentists proceed. The muscles of the jaws often close under the use of chloroform and ether, and they try to open the mouth partly by persuasion, partly by force- irritating and rousing the patient. A cork or gag placed betwen the teeth before the inhalation is commenced, saves all this, and expedited and facilitates the whole process.

${ }^{4} \mathrm{I}$ believe all the reputed failures and misadventures are attributable to two causes, viz., 1. using an impure and imperfect variety of chloroform; and 2. not giving it in sufficiently large and rapid doses. 
operation; and, without moving, he was carried out of the operation theatre of the hospital still fast asleep. When visited some time afterwards, he was found awake in bed, with a bright merry eye, as if just out of a refreshing sleep. No pain even then. - III. A nervous woman, a patient of Mr. Millers, was to undergo partial amputation of the foot in the hospital - afraid both of the operation, and of being carried in before a crowd of medical men for the purpose. I apathized her with chloroform in the consulting room of the hospital, had her carried into the operation-room in that state, and did not allow her to awake till the amputation was perfomed, and she was removed back again to bed. She was thus entirely spared both the moral shock and physical pain which she dreaded. - IV. A boy had his elbow-joint excised by Mr. Syme. The operation, which is always a very painful one, was prolonged in consequence of the very diseased state of the parts operated on. He slept soundly, and remained perfectly and passively still during the whole operation. \& c. \& c.

Uses in $m$ id wif ery. - To diminsh and annul the physical pains attendant on labour, and more especially those which accompany the passage of the child's head through the pelvic cavity and outlet, (the second stage of Denman).

Ex a m ples. - I. The lady to whom it was first exhibited had been previously delivered in the country by craniotomy after a very long labour. Her second confinement took place a fortnight before the full time. Chloroform was begun to be inhaled when the os uteri was becoming well expanded, and the pains very severe. In twenty-five minutes the child was born. The mother did not awake till after the placenta was removed; and was perfectly unaware that her child was born and alive. She stated her sensation to be those of awakening from "a very comfortable sleep». - II. I exhibited it, with Mr. Carmichael, to a patient who had, at her preceding confinement, been in severe labour for twenty hours-followed by flooding. She began the inhalation when the dilatation of the os uteri was half completed. The child was born in fifty minutes afterwards. She was kept under its influence for a quarter of an hour longer till the placenta was removed, and the binder, body, and bedclothes all adjusted. On awaking, she declared she had been sleeping refreshingly; and was quite unconscious that the child was born. No flooding. An hour afterwards, she declared she felt perfectly unfatigued, and not as if she had borne a child at all. - III. Patient unmaried. A first labour. Twins. The first child presented by the pelvis, the second with the hand and head. The chloroform was exhibited when the os uteri was fully dilated. The passages speedily became greatly relaxed (as has happened in other cases placed under its influence), and in a few pains the first child was born, assisted by some traction. I broke the membranes of the second, pushed up the hand, and secured the more complete presentation of the head. Three pains expelled the child. The mother was then bound up; her clothes were changed; and she was lifted into another bed. During all this time she slept on soundly, and for a full hour afterwards; the chloroform acting in this, as in other cases of its 
prolonged employment as a soporific. The patient recollected nothing from the time of the first inhalations, and was greatly distressed when, not one, but two living children were brought by the nurse to her. Dr. Christison saw this case with me. I have used it in several operative deliveries with similar success.

In labour it does not require to be given in such large doses as in surgery. After the first $\mathrm{f}$ ull dose, a few inhalations before each returning uterine contraction is generally sufficient. It should be made more deep as the head is passing the perineum and vulva. If the state is extremely and unnecessarily deep, it will no doubt diminish and even temporarily stop uterine contractions; and $I$ have taken advantage of this, in one case, in facilitating the operation of turning, \& c. Besides thus, 1. Diminishing or annulling the more severe part of the sufferings attendant on natural labour, it will, 2. Abolish those more agonizing pains which accompany the use of the forceps, and other modes of operative delivery; 3 . Enable us to extract the placenta artificially when required, without resistance or suffering; and 4 . Give us the power of making an accurate and full examination of the presentation, when necessary early in labour, as in placenta previa, preternatural presentations, \& c.

U s e s in M edicin e. - 1 . As an anti-spasmodic; as in asthma, laryngismus, tetanus, and other spasmodic diseases, \& c. I have used successfully the inhalation of ether to arrest the paroxysmus of hooping-cough, dysmenorrhoea, colic, and the pains attendant on the passage of biliary calculi. In a case of the most severe, at the same time painful, spasmodic twisting and convulsions of the extremities attending a second attack of chorea, I allowed the patient ether-inhalation; and sometimes she lay under its influence for hours, with relief while its action lasted, but generally without sleep. Latterly the chloroform has both relieved the spasms and their attendant pain, and procured sleep. - 2. As an a nodyne or narcotic. In neuralgia, I have seen chloroform stop the fit at once; in two other cases the pain remained absent only while the chloroform acted. A patient suffering under severe delirium tremens had remained awake for about seventy hours; a half ounce of laudanum, given at a single dose, failed to produce rest; ten hours afterwards, the inhalation of chloroform was immediately followed by several hours of critical sleep. What cases of insanity would it benefit? I have exhibited it in full doses in some cases of dementia, combined with excitement and wakefulness. They were all asleep in about a minute - and remained so for some time. In nothing does chloroform differ from ether more than in its soporific effects when given in full doses, and continued for some time. - 3. In small doses as a diffusible stimulant; to arrest the first commencement of ague, ephemera, \& c.; in hysteria \& c. Perhaps it may be used by inhalation in small quantities when the stomach will not bear wine or other stimulants.; in severe vomiting, fevers, \& C. I have seen its inhalation at once dispel a sick head ache. - 4. A s a c o $\mathrm{nt}$ ro-s $\mathrm{t}$ i m u lant in inflammatory diseases, especially those of a painful character?? Acute rheumatism, \& c.??

C a u tions. - The liquid used should be sufficiently strong. Its proper 
sp. gr. is (as I have said) 1,480. I have seen some specimens perfectly unfit for use from their weakness.; others perfectly unfit from their want of purity, for although of the proper specific gravity, they contained free chlorine, irritating the throat, and making the patient cough. It is certainly far too powerful an agent to be entrusted to nurses or unprofessional individuals. I have given it, up to this date, to above eighty persons, without the slightest bad result of any kind whatever in any one of them. The power, however, which we have with it, of bringing down the pulse, \& c., shows that, if exhibited in too st $r o n g$ a dose, given $u n i n t e r r u p t e d l y$ for too great a length of time, it would doubtless produce serious consequences, and even death. But, certainly, all its $\mathrm{f}$ ull anaesthetic and other influences may be perfectly obtained without allowing it to produce such depression as would be in any degree dangerous. I have, in obstetric cases, kept patients under its influence for several consecutive hours, without any resulting harm of any kind to either mother or child; renewing its application from time to time after the first full dose. Like many other agents, it may be powerful for evil as well as for good. I believe its great potency will be one great safeguard against its abuse.

Its influence upon the blood, \& c., the counter-indications to its use, \& c. \& c., remain still to be ascertained.

Edinburgh, 25 the November 1847.

(From Report of the Proceedings of the Medico-Chirurgical Society of Edinburgh, on November $10^{\text {th }}$, as given in the Monthly Journal of Medical Science for December 1847, p. 451.)

Historical researches regarding the superinduction of insensibility to pain in surgical operations; and announcement of a New Anaesthetic Agent.

By Professor Simpson.

Dr. Simpson first entered at some lenghth into the chemical and therapeutic history of sulphuric ether. He traced it from Lully, Hollander, Valentine, \& c., in the $13^{\text {th }}$ and $14^{\text {th }}$ centuries, down to Valerius Cordus, who described its formation accurately in the $16^{\text {th }}$ century; and Frobenius, who first designated it ether, and published an account of it in the Philosophical Transactions of 1730. He then pointed out its therapeutic history, from the first mention of it as a medical agent by Valerius Cordus, down to the works of Hoffman, Cullen, Alston, Lewis, Monro, and the other writers of the materia medica during the last century. The history of its use by inhalation commences with the pamphlet of Richard Pearson, published upon it in 1795. Since his time most therapeutic authors mentioned, more or less fully, its employment by inhalation in asthma, \& c., as Duncan, Murray, Brande, Christison, Thomson, Pereira, Nysten, Barbier, Wendt, Vogt, Sundelin, \& c. Its power of producing, by inhalation, effects like intoxication, or like the influence of nitrous oxide gas, he showed to have been stated by various American authors, as by Godman (1822), Mitchell (1832), Professor Samuel Jackson (1833), Wood and Bache (1834), Miller (1846), before it was so fortunately adopted by Dr. Morton as an anaesthetic agent. His belief was, that Professor Charles Jackson improperly 
claimed the merit pertaining to its recent happy application to surgery \&c. Perhaps the idea of relieving patients from the pains of surgery by some such means, or rather the restoration of that idea in recent times (for it was an old one), belonged justly to Horace Wells.

Dr. Simpson then proceded to show, that the idea was not one entirely of our own times, by taking a retrospective glance at the history of $p$ a in les s operations. Among external measures proposed with this view, he mentioned 1. The idea of Moore (1784) to compress and obtund previously the nerves of the implicated part, an idea, however, which, long before Moore's time, was suggested by Ambrose Paré; and 2. the alleged ligature or compression of the larger vessels of the neck mentioned by Hoffman, Valverd̦i, Morgagni, \&c.

Dr. S. then showed that various in ternal agents, introduced by inhalation and otherwise, had been at different times suggested and employed; as 1 . In 1828, the previous inspiration of carbonic acid (?) gas proposed by Dr. Hickman; 2. In 1800, the hint of Davy regarding the application of nitrous oxide for this purpose; 3 . The inhalation of vapour arising from the watery extract of mandragora, opium, \&c. He read at length the following remarkable passage, (which he had found in the old surgical treatise of Theodoric, who died in 1228, ) as an odd forestalling of the practices of the present day. In the rubric of the work the receipt is described as « Spongia somnifera,» and described thus: -

"The preparation of a scent for performing surgical operations, according to Master Hugo; it is made thus: - Take of opium and of the juice of the unripe mulberry, of hyoscyamus, of the juice of the hemlock, of the juice of the leaves of mandragore, of the juice of the woody ivy, of the juice of the forest mulberry, of the seeds of lettuce, of the seed of the burdock which has large and round apples, and of the water hemlock, each $\xi \mathrm{i}$; mix the whole of these together in a brazen vessel, and then in it place a new sponge, and let the whole boil; and as long as the sun on the dog-days, till it (the sponge) consumes it all, and let it be boiled away in it (or, in other words, let a watery extract be so formed). As often as there is need of it place this same sponge into warm water for one hour and let it be applied to the nostrils till he who is to be operated on ( $q u i$ incidendus e st) has fallen asleep, and in this state let the operation be performed (et sic fiat chirurgia). When this is finished, in order to rouse him, place another sponge dipped in vinegar frequently to his nose; or let the juice of the roots of fenigreek be squirted into his noştrils. Presently he awakens.»

The above remarkable anaesthetic means was recommended in the thirteenth century. But mandragore was used even much earlier for the same purpose. In proof of this Dr. Simpson adduced various extracts from the works of authors of the Augustine age, as Dioscorides, Pliny, and Apuleius, \&c.; as, for example, the following from Dioscorides - chapter on mandragore -

1. "Some boil down the roots in wine to a third part, and preserve the juice thus procured, and give one cyathus of it in sleeplessness, and in severe pains of whatever part; also (it is given) to cause the insensibility $(\pi \circ \iota \varepsilon \iota v(\iota v \iota \iota \sigma \quad \Theta \eta \sigma \iota \iota v)$ of thos e who a r e to be cut or c a t e rized.» 
2. "There is prepared also, besides the decoction, a wine from the bark of the root, three $\mathrm{min}$ o e being thrown into a cask of sweet wine; and of this three cyathi are given to those who are to be cut or cauterized, as aforesaid; for, being thrown into a deepsleep, they do not perceive pain.»

3. Again, of another mandragore called "M o r i on", Dioscorides observes, «medical men use it also for those who are to cut or cauterized.»

When treating of mandragore, Apuleius in the same way remarks, "if anyone is to have a member mutilated, burned, or sawed ( $\mathrm{m} \mathrm{util}$ an $\mathrm{d} \mathrm{u} \mathrm{m,} \mathrm{co} \mathrm{m} \mathrm{-}$ b u re n d u m, vel se r randum), let him drink half an ounce with wine, and let him sleep till the member is cut away without any pain or sensation (et tantum dormiet, quousque abscindatur membrum aliquo sine dolore et sensu).

In describing the leaves of circeius or mandragore, Pliny remarks, "It has a soporific power on the faculties of those drinking it. An ordinary potion is half a cup. It is drunk against serpents, and b e for e cuttings and punctuaries, lest they befelt. (Bibitur et contra serpentes, et ante sectiones punctionesque, ne sentiantur).» The same author mentions that the seeds of rocket (e $\mathbf{r} \mathbf{u}$ a), when drunk infused in wine by criminals about to undergo the lash, \& c., produce a certain callousness or hardihood of feeling ( $d u r i t i a m$ quandam contra sen s u m indue re). Dr Simpson referred to Bang or Indian hemp being used in India with the same object at the present day; and cited various authorities to show that the gall and vinegar, or myrrhed wine offered to our Saviour before his crucifixion, was probably at that time generally employed with the same object. Dr. Simpson referred to the inhalation of the intoxicating vapours of hemp-seed, as having been practised by the Scythians long before the Christian era, as described by Herodotus, \& c.

After some further similar observations, Dr. Simpson proceeded to draw the attention of the Society to the use of Chloroform, the powerful anaesthetic agent which he had lately discovered, in making a series of experiments on different respirable substances. The substance of these observations has been published in a separate pamphlet.

Dr. B e n n e t t stated that he had inhaled the chloroform, the taste of which was exceedingly pleasant. It had produced a warm glow throughout the chest, which seemed rapidly to affect the brain. After a few inspirations, he felt that one more would render him perfectly insensible, and therefore discontinued it. He had never inhaled ether, and could not speak as to its comparative merits. But the absence of all apparatus, the simple pockethandkerchief, and agreeable odour, had induced him to try the new preparation, and he had not experienced any unpleasant effects.

D r. Ro bert so n stated that he also had inhaled the chloroform. He had frequently employed ether to remove a severe tic in the foot, and could assure the society that the new preparation was infinitely more agreeable and certain in its effects than ether. In a young lady labouring under dysmenor- 
rhoea, and affected with suppuration of the ankle joint, whose cries were distinctly heard in the street, he had lately seen the best effects from ether inhalation, which at once removed the pain, and abled her to enjoy a tranquil sleep. Four menstrual periods have since passed without pain. He had also seen it employed during the operation of firing in horses, which produced no pain, nor even the slightest perspiration. In another case of lock-jaw in a horse, occasioned by a fall into a quarry, and which had prevented deglutition for four days, ether inhalation had completely and permanently removed it.

Dr. S i m p s o $\mathrm{n}$ requested that the President would nominate a committee to investigate experimentally the properties of the new substance, and report at the next meeting. This was agreed to, and the following gentlemen were appointed for that purpose. Dr. Hughes Bennet, C o nven e r-Drs. Alison, Christison, D. Maclagan, Taylor, Duncan, and Roberts, with power to add to their number.

The Society then adjourned, when a very singular scene took place. Dr. Simpson having stated that any gentleman who felt inclined might try the effects of chloroform on his own person, Mr. Young, cutler, at once presented himself. About a tea-spoonful of the preparation was placed on a silk pockethandkerchief, folded together in the hand. After a few inspirations, complete insensibility was produced, on recovering from which, he said that he had experienced exactly the same sensations as when he had taken ether. Dr. Roberts then inspired from the handkerchief, with the same result. Several other gentlemen followed in succession. In one (Mr. Hunter) some excitement was produced. He took a small exhilarating dose, stood up, and on being held made some resistance. He afterwards declared that the effect produced on him was similar to that occasioned by the nitrous oxide gas. Whilst the bustle attendant on this case was in progress, the handkerchief seemed to have circulated among the members, who applied it to their faces, and were unexpectedly surprised by the effects produced on them; so that, when we looked round, we saw more than one gentleman insensible, and several others in various stages of apparent intoxication. They all however rapidly recovered, and declared that they had experienced no unpleasant symptom; whilst a few stated their sensations to have been so delightful, that they should have no objection to their repetition.

\section{Postscript on the preparation of chloroform}

I have seen different instances reported in the English and French Journals of patients requiring to inhale chloroform for five, ten, and even twenty minutes, before they came under its influence. In all such cases, the chloroform used must have been of a most inferior quality. I have generally seen patients affected in about a minute; they rarely resist it for above two minutes; and never, or almost never, for above three. The chloroform which I have mostly used, is that manufactured by Messrs. Dunean, Floekhart, and Co., chemists, Edinburgh. It ist made according to the following formula of Dumas: - 
$\mathrm{R}$ Chloride of lime in powder, , . , , . . . . lb. IV.

Water . . . . . . . . . . . . . . . . lb. XII.

Rectified Spirit, . . . . . . . . . . . . . f f $£$ XII.

Mix in a capacious retort or still, and distill as long as a dense liquid, which sinks in the water with which it comes over, is produced.

The product obtained by the above process, is rectified by agitating it with several portions of strong sulphuric acid, and afterwards distilling it from carbonate of baryta. D., F., \& Co. inform me, that they always distil it a th i r d time from lime, and that they believe it would be impossible for them to furnish it perfectly pure without this. Latterly, they have made and sent out from 60 to $80 \mathrm{oz}$. per diem $(2 \mathrm{~s}$. per oz.) manufactured by this process. In the observations which I previously published, I inadvertendly omitted to state and insist upon the purifying part of the process. 